\title{
Clinical and Bacteriological Diagnosis of Foot-rot in Beef bulls in Basra
}

\author{
Wessam Monther Mohammed Saleh*, Hussein Ali Naji, Mohanad H Lafta, Saad Hashim Al-Husseiny, Fatima Ali \\ Abood and Shifaa Kareem Yassir
}

Department of Internal and Preventive Medicine, Iraq

Received: 阱January 21, 2019; Published: 制January 31, 2019

*Corresponding author: Wessam Monther Mohammed Saleh, Department of Internal and Preventive Medicine, Iraq

\begin{abstract}
Foot rot is a common disease of small ruminants and cattle that cause world-wide economic losses in animal's production. Fusobacterium necrophorum is attributed to be involved in the primary causes of foot-rot in cattle. We applied bacteriological and biochemical tests to analyze specimens collected from the hooves of bulls with symptomatic foot-rot for the presence of $F$. necrophorum in conjugation with complete blood count analysis. Out of thirty-one samples tested, twenty-nine had positive to F. necrophorum. Of the thirty-one blood samples, we did not find significant differences in hemogram profile than normal in the acute phase of the disease while significant changes in leukogram were noticed. The recurrent detection of F. necrophorum within beef bulls' herds in Basra Province is noticeable that suggests a substantial role of this organism in hoof infection of cattle.
\end{abstract}

Keywords: Foot-Rot; Fusobacterium Necrophorum; Bulls, Clinical Signs; Biochemical Tests; Cbc

\section{Introduction}

Foot-rot is an acute and extremely infectious bacterial disease that generates lesions on the subcutaneous tissues and skin of the interdigital space of ruminants [1]. The disease is caused by Fusobacterium necrophorum. A rod shaped gram-negative aerotolerant anaerobe opportunistic bacterium; that presents normally in the feces and rumen of cattle and in their environment [2]. Fusobacterium necrophorum has the ability to cause considerable hepatic abscessation in cattle, sheep and camel [3]. Two subspecies of this bacterium were recognized; F. necrophorum sub-species necrophorum F. necrophorum and F. necrophorum subspecies fundulforme. The sub-species necrophorum is detected more frequently in foot-rot infections than the sub-species funduliforme as a result of its intensive virulence [4]. Several secreted products and/or toxins have involved as virulence factors. Haemagglutinin, endotoxin and leukotoxin [5], haemolysin and adhesion [2] are the main factors assisting the ruminal localization and liver invasion. Among these toxins, "endotoxin" and "leukotoxin" are thought to be more effective than others in overcoming the hosts defense mechanism to induce the infection [2,5]. Many attempts for providing a protective immunity against $F$. necrophorum by using toxoid, whole cell bacterin or other cytoplasmic compositions have been investigated. Unfortunately, none of the prototype immunogens has been introduced a satisfy immunity against fusobacterial infection. Therefore, the control of foot-rot has mainly based on the using of the anti-microbial therapy [6]. When there is injury to the skin of the interdigital space especially where the cattle are located on muddy and contaminated areas, F. necrophorum can invade causing the disease. Then the infected cattle will further spread the organism to the environment and to other susceptible [7]. The high cost of treatment and sharp decrease of weight gain leading to heavy economic losses in cattle industry [8]. Cattle with severe hooves infection might require to be euthanized, while the lame bulls could not breed accordingly. The economic impact of this disease will be minimized through appropriate preventive methods and early treatment. Minerals deficiency (Zink, Selenium and Copper) could probably increase the incidence of foot-rot [9].

Little is known on the pathogenicity of $F$. necrophorum in footrot infection with no single study has been clarified the sub-species of this organism that presents in hooves in Basra. Therefore, in the current study, we used clinical, bacteriological and biochemical analysis on hoof samples from foot-rot infected bulls to identify the F. necrophorum, and to study its role on the blood parameters.

\section{Methodology}

The current study was done to investigate the causes of hooves lesions of bulls in a private beef cattle farm that located at the south 
of Basra province during October 2017. Thirty-one beef bulls aged between 2 - 2.5 years were found to have hoof lesions, all bulls were inspected clinically, and all the affected animals were treated accordingly. Blood and hoof swab samples were collected and analyzed as following:

\section{Hematological Analysis}

Jugular blood was collected in EDTA tubes for Complete Blood Count (CBC) analysis. The samples were analyzed manually in clinical pathology laboratory, department of internal and preventive medicine, college of veterinary medicine / university of Basra. The examined parameters were: Red Blood Cell Counts (RBCc), Hemoglobin (Hb), Packed Cell Volume (PCV), Mean Corpuscular Volume (MCV), Mean Corpuscular Hemoglobin Concentration (MCHC), total White Blood Cell Count (WBCc), Lymphocyte Count (Lymp), Segmented Neutrophils Count (S Neut), Monocyte Count (Mono), Eosinophil Count (Eosin) and Basophiles Count (Baso).

\section{Bacterial Isolation and Identification}

Hoof scrapings of the thirty-one lame bulls were collected anaerobically. Samples were cultured directly on Macconkey and Blood agar culture in $\mathrm{CO}_{2}$ jar at $37^{\circ} \mathrm{C}$ for 48 hours in Central Research Unite, College of Veterinary Medicine / University of Basra.

Initial bacterial determination based on the characteristic morphology of the growing colonies and the organism. When the colonies irradiated with UV light, a greenish fluorescence appearance can be noticed. Butyric acid odor also can be smelled. Microscopi- cally, characteristic rod shape gram negative pleomorphic morphology of the bacterium was noticed. In addition, the identification was appended by the susceptibility to metronidazole and kanamycin on primary inoculated agar plate. To confirm the identification of $F$. necrophorum, a marked $\beta$-hemolysis on blood agar enriched with $5 \%$ sheep blood in conjugation with resistance to vancomycin and susceptibility to polymyxin and the specific biochemical tests were applied as described by [10].

\section{Statistical Analysis}

All data were analysed using JMP ${ }^{\circledR} 11$. NC: SAS Institute Inc. software version. The data were considered significant at $(\mathrm{p}<0.05)$. Pair Student's " $t$ " test was applied to determine the differences.

\section{Results}

\section{Clinical Examination}

The symptoms of the disease were recorded as following:

Sudden onset of lameness accompanied with decrease appetite (Table 1). The bulls were often only touching their toe to the ground due to sever painful lesions. More than one limb was often infected, commonly the fore-limbs. The tissues of the interdigital space were reddish and swollen that consequently leads to separate a part of the hoof. Skin between toes of some infected bulls develops a crack (Figures 1-3). Moderate to severe fever with significant increase of respiratory and heart rates (Table 1). There was a marked foul smell.

Table 1: Clinical and bacteriological examination results of the infected bulls.

\begin{tabular}{|c|c|c|c|c|c|}
\hline $\begin{array}{c}\text { Temperature (-C) } \\
\text { Mean } \pm \text { S. E. } \\
(\text { NO. }=\mathbf{3 1})\end{array}$ & $\begin{array}{c}\text { Respiratory Rate } \\
\text { Mean } \pm \text { S. E. } \\
\text { (NO. = 31) }\end{array}$ & $\begin{array}{c}\text { Heart Rate Mean } \pm \text { S. } \\
\text { E. (NO. = 31) }\end{array}$ & $\begin{array}{c}\text { Hoof Lesion (\%) } \\
\text { (NO.= 31) }\end{array}$ & $\begin{array}{c}\text { Lameness (\%) } \\
\text { (NO. = 31) }\end{array}$ & $\begin{array}{c}\text { F. necrophorum } \\
\text { identification (\%) } \\
\text { (NO.= 31) }\end{array}$ \\
\hline $40.51 \pm 0.42$ & $44.23 \pm 0.50$ & $89.14 \pm 0.91$ & 100 & 100 & 94 \\
\hline
\end{tabular}

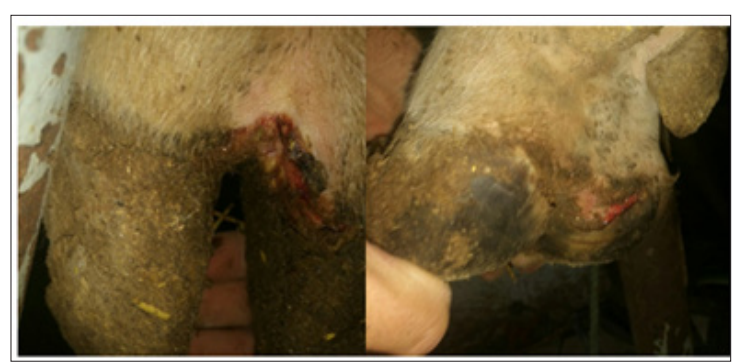

Figure 1: Case of infected hoof showing: Crack, swelling and dead tissues in the interdigital space.

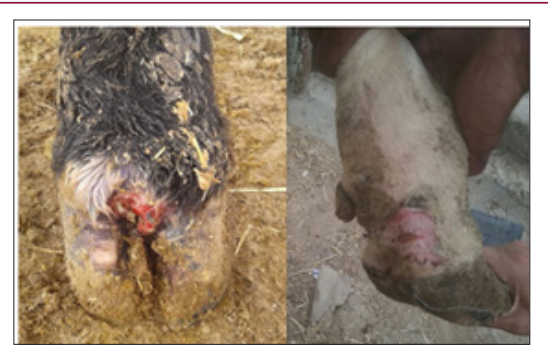

Figure 2: Case of infected hooves showing: swelling, necrotic area, crack and dead tissues in the interdigital space.



Figure 3: Case of infected bull showing: Signs of restlessness and lameness.

\section{Isolation and Identification of $F$. necrophorum}

Of thirty-one swabs taken from symptomatic foot-rot bulls, twenty-nine were found to be positive, according to the morphology 
of the colonies (Figures 4-6) and the biochemical characteristic of the organism (Table 2). The colonies appearance was: circle in shape, slightly elevated with smooth edge, moveable when touched has a white buff with a waxy appearance, occasionally the color changed to light yellow. Marked $\beta$-hemolysis zoon around the colonies of $F$. necrophorum is seen on the blood agar. Nevertheless, two swabs that have collected from the infected hooves gave negative results to the microbiological examination.

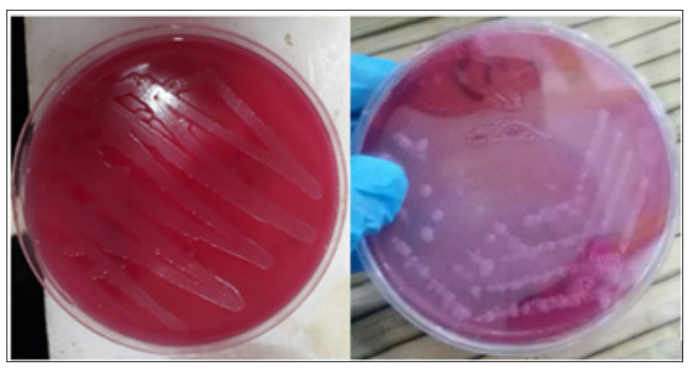

Figure 4,5: A characteristic morphology of F. necrophorum culture colonies on Macconkey agar.

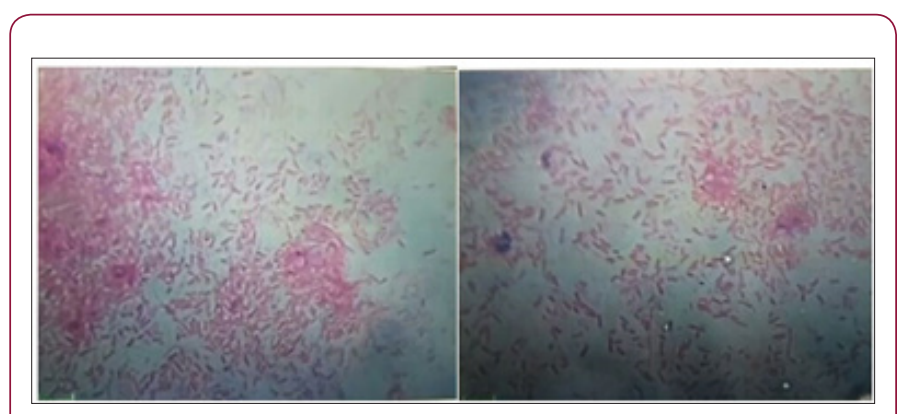

Figure 6: Photomicrograph of a Gram stain bacterial smear showing a characteristic Gram-negative rode shape F. necrophorum.

\section{Complete Blood Count}

The mean of hemogram parameters that recorded in the current study were with the normal values, while marked changes in total white blood cell, monocytes and lymphocytes percentages were recorded (Table 3).

Table 2: Results of the biochemical characterization of F. necrophorum.

\begin{tabular}{|c|c|c|c|c|c|c|c|}
\hline $\begin{array}{c}\text { Gram } \\
\text { Stain }\end{array}$ & Indole & Thrionine & $\begin{array}{c}\text { Lactate to } \\
\text { propionate }\end{array}$ & Lipase & Catalase & Phosphatase \\
\hline- & & & + & + & - & - \\
\hline Nitrate & Gelatin & Manitol & Meat digestion & Escolin & Desoxy-cholate & Sugar Fermentation \\
\hline & & - & - & - & + & Production \\
\hline
\end{tabular}

Table 3: Complete Blood Count Analysis Results of the Infected Bulls (Means \pm S.E.).

\begin{tabular}{|c|c|c|c|c|c|c|c|c|c|c|c|}
\hline RBC & $\mathrm{Hb}$ & PCV & MCV & MCH & MCHC & WBC & S Neut & Lymp & Mono & Eosin & Baso \\
\hline$\left(\mathrm{x} 10^{12} / \mathrm{L}\right)$ & $(\mathrm{g} / \mathrm{L})$ & $(\mathrm{L} / \mathrm{L})$ & $(\mathrm{fL})$ & $(\mathrm{Pg})$ & $(\mathrm{g} / \mathrm{L})$ & $\left(\mathrm{x} 10^{9} / \mathrm{L}\right)$ & $(\%)$ & $(\%)$ & $(\%)$ & $(\%)$ & $(\%)$ \\
\hline 8.8 & 10.67 & 35.33 & 39.81 & 9.27 & 30.25 & 10.49 & 28.08 & 52.42 & 17.17 & 2.33 & 0.00 \\
\hline \pm 0.72 & \pm 0.55 & \pm 1.79 & \pm 2.83 & \pm 1.58 & \pm 0.08 & \pm 0.76 & \pm 3.45 & \pm 1.56 & \pm 2.24 & \pm 0.31 & \pm 0.00 \\
\hline
\end{tabular}

\section{Discussion}

Foot-rot is a major problem to animal welfare that leading to reduction in productivity [8]. Fusobacterium necrophorum is the main etiology of foot-rot, and an opportunistic bacterium that could causes other conditions such as: hepatic abscesses [3], oral and laryngeal coccobacillus's [2]. Understanding the pathogenicity of $F$. necrophorum and which strain are present in endemic footrot areas, are of value for satisfy treatment, control and eradication of the disease. Little information is available of the genetic variety of $F$. necrophorum in Iraq. To our knowledge, the current study is the first for identification of F. necrophorum on hooves swaps that have been collected from infected bulls in Basra province. The high absolute (94\%) positive reporting of $F$. necrophorum from affected toes highlights it's important role in foot-rot infection, and supporting the findings of previous researches that have been done by $[2,4,5,7,8,11-15]$. Moreover, $F$. necrophorum is almost presents on the toes of the lame cattle.

In this study, we were focusing on F. necrophorum as a primary cause of bovine foot-rot. Detection only a single variation from any individual sample could be indicated that the pathogen variants are very specialized and there was a lack in train diversity as well as the little number of foot-rot specimens. Further molecular analysis can reveal more details of this pathogen. Fusobacterium necrophorum population in rumen is greater in grain feed than forage feed animals. Consequently, to rumenitis and ruminal acidosis of grain-fed cattle, the bacteria gain access to the portal circulation then localized in liver causing abscessation [5]. In this study, $F$ necrophorum was detected from swabs have taken from the hoof of bulls. This finding proposes that the organism might be transmitted to and from the mouth and rumen of cattle to the beef farm, so far by an un-characterized pathway. In our research, all the examined bulls were shown to have a sever hoof lesion which could be as a role of leukotoxin. In cattle, it is possible that the leukotoxin that secreted from bovine $F$. necrophorum plays a key role in the creation of necrotic infections [16-18].

A complete blood count used to be suitable as a screening assessment for underlying certain illness such as infectious diseases or anemia $[19,20]$. To our knowledge, this work is the 
first study to demonstrate the effect of foot-rot infection for local strain of $F$. necrophrum on beef cattle in Basra and relationship of this bacterium on hemogram and leukogram changes after footrot infection. In the current study, the hemogram parameters that recorded in all infected bulls were within the normal range suggesting that there were no severe effect of the virulence of $F$. necrophorum on the hemogram parameters during the acute phase of the disease. Unfortunately, we did not collect blood samples prior the onset of foot-rot infection and hemogram values could be higher before infection. However, chronic Fusobacterial infection such as liver abscessation could induce a significant alteration in blood parameters of beef bulls [21].

On the other hand, the increase in leukogram values especially monocytes and lymphocytes suggest an inducing of inflammatory reaction which needs further production of monocytes to play its role as phagocytes as a response to $F$. necrophorum infection or due to the bad management, environmental factors and previous infection that subsequent contribute to develop of foot-rot in the beef bulls [1].

\section{Conclusion and Recommendation}

This study reports the initial data on F. necrophorum in beef cattle flock with different clinical aspects of foot-rot in Basra province regarding virulence of the organism. Fusobacterium necrophorum is often found on the hooves of lame beef cattle in Basra. The risk of this organism in lame beef herds might be of value for management of other susceptible animals as F. necrophorum is believe it to be implicated in foot-rot likewise as reported in [13]. Therefore, further studies should be done for molecular analyze to the genetic variety of this organism. Study the rule of bacterial toxicity and the virulent factor of the bacterium to understand the pathogenesis of foot-rot also needed. Additionally, highlight the importance or foot-rot as a threat of animal heath welfare and its economic losses in beef cattle.

\section{Acknowledgment}

We would like to express our special thanks of gratitude to the farmers in beef farm and to the staff of Clinical pathology laboratory / College of Veterinary Medicine / University of Basra that represented for their cooperation and helping us in implementing this research.

\section{References}

1. Van Metre DC (2017) Pathogenesis and Treatment of Bovine. Vet Clin North Am Food Anim Pract 33(2): 183-194.

2. Nagaraja TG, Narayanan SK, Stewart GC, Chengappa MM (2005) Fusobacterium necrophorum infections in animals: Pathogenesis and pathogenic mechanisms. Anaerobe 11(4): 239-246.

3. Al Nakeeb, NK, DRH Al Fetly (2016) Anaerobic bacterial isolation with histopatholgical exam of liver abscesses in cattle, sheep, and camels in Al-Qadisiyah province AL-Qadisiyah. J of Vet Med Sci 15(2): 40-46.
4. Shinjo T, T Fujisawa, T Mitsuok (1991) Proposal of two subspecies of Fusobacterium necrophorum (Flügge) Moore and Holdeman: Fusobacterium necrophorum subsp necrophorum subsp nov, nom rev(ex Flügge 1886), and Fusobacterium necrophorum subsp funduliforme subsp nov, nom rev(ex Hallé 1898) International. J of Systematic \& Evolutionary Microbiol 41(3): 395-397.

5. Tadepalli S, Narayanan SK, Stewart GC, Chengappa MM, Nagaraja TG (2009) Fusobacterium necrophorum: a ruminal bacterium that invades liver to cause abscesses in cattle. Anaerobe 15(1-2): 36-43.

6. Tan Z, T Nagaraja, M Chengappa (1996) Fusobacterium necrophorum infections: virulence factors, pathogenic mechanism and control measures. Vet Res Commun 20(2): 113-140.

7. Edmondson A (1996) Interdigital necrobacillosis (footrot) of cattle Large Animal Internal Medicine 2: 1314-1315.

8. Green L, T George (2008) Assessment of current knowledge of footrot in sheep with particular reference to Dichelobacter nodosus and implications for elimination or control strategies for sheep in Great Britain. Vet J 175(2): 173-180.

9. Currin JF, WD Whittier, N Currin (2005) Foot rot in beef cattle.

10. Quinn PJ, B Markey, FC Leonard, P Hartigan, S Fanning, et al. (2011) Veterinary microbiology and microbial disease. John Wiley \& Sons pp. 893.

11.Ji X, J Ren (2002) Determination of copper and zinc in serum by derivative atomic absorption spectrometry using the microsampling technique. Analyst 127(3): 416-419.

12. Bennett G, Hickford J, Sedcole R, Zhou H (2009) Dichelobacter nodosus, Fusobacterium necrophorum and the epidemiology of footrot. Anaerobe15(4): 173-176.

13. Bennett G, Hickford J, Zhou H, Laporte J, Gibbs J (2009) Detection of Fusobacterium necrophorum and Dichelobacter nodosus in lame cattle on dairy farms in New Zealand. Res Vet Sci 87(3): 413-415.

14. Narongwanichgarn W, Misawa N, Jin JH, Amoako KK, Kawaguchi E, et al. (2003) Specific detection and differentiation of two subspecies of Fusobacterium necrophorum by PCR. Vet Microbiol 91(2-3): 183-195.

15. Zhou, H, G Bennett, JG Hickford (2009) Variation in Fusobacterium necrophorum strains present on the hooves of footrot infected sheep, goats and cattle. Vet Microbiol 135(3-4): 363-367.

16. Emery, D, J Dufty, B Clark (1984) Biochemical and functional properties of a leucocidin produced by several strains of Fusobacterium necrophorum. Aust Vet J 61(12): 382-387.

17. Tan ZL1, Nagaraja TG, Chengappa MM (1992) Factors affecting the leukotoxin activity of Fusobacterium necrophorum. Vet microbiol 32(1): $15-28$.

18. Ludlam HA, Milner NJ, Brazier JS, Davies IH, Perry K (2009) lktA-encoded leukotoxin is not a universal virulence factor in invasive Fusobacterium necrophorum infections in animals and man. J Med Microbiol 58(4): 529-530.

19. Keohane, EM, LJ Smith, JM Walenga (2015) Rodak's hematology: clinical principles and applications 2015: Elsevier Health Sciences.

20. Wu X, Zhao M, Pan B, Zhang J, Peng M, et al. (2015) Complete blood count reference intervals for healthy Han Chinese adults. PloS one 10(3): e0119669.

21. Macdonald AGC, Bourgon SL, Palme R, Miller SP4, Montanholi YR (2017) Evaluation of blood metabolites reflects presence or absence of liver abscesses in beef cattle. Vet Rec Open 4(1): e000170. 


\section{ISSN: 2574-1241}

DOI: 10.26717/BJSTR.2019.13.002472

Wessam Monther Mohammed S. Biomed J Sci \& Tech Res

(C) (i) This work is licensed under Creative

Submission Link: https://biomedres.us/submit-manuscript.php

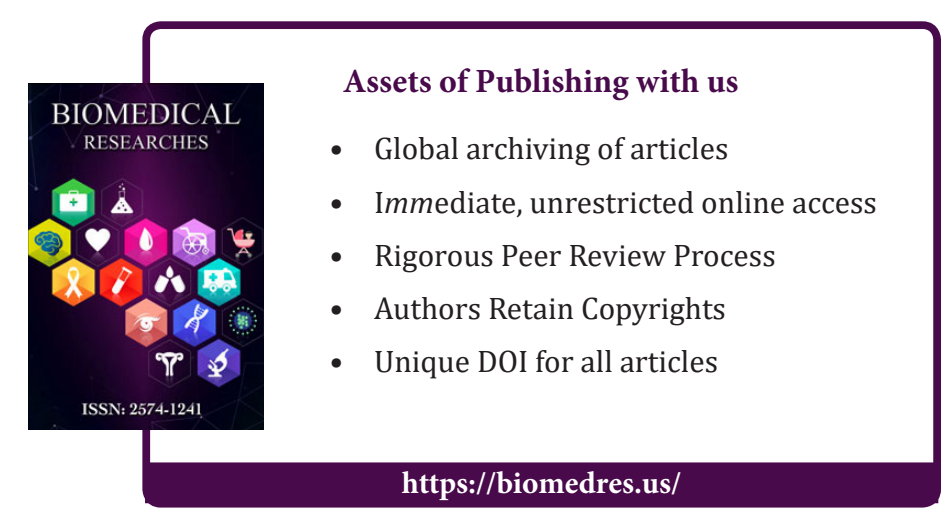

